\title{
Parametric study of multiple configurations of pico hydrokinetic turbines using CFD
}

\author{
Yogaraja Balakrishnan ${ }^{1}$ and At-Tasneem Mohd Amin 2 ,a \\ ${ }^{1}$ Faculty of Mechanical Engineering, Universiti Malaysia Pahang, 26600 Pekan, Pahang, Malaysia \\ ${ }^{2}$ Fellow Researcher, Centre for Earth Resources Research \& Management (CERRM), Universiti Malaysia Pahang, Lebuhraya Tun Razak, \\ 26300 Gambang, Kuantan, Pahang, Malaysia
}

\begin{abstract}
This paper aims to study the river flow characteristics over pico hydrokinetic turbines with variation of arrangement using computational fluid dynamics (CFD) software. This study is required to obtain the optimum spacing and angle between the turbines which leads to higher turbine effective utilisation and performance in terms of power generated. In this study, a river model is created in CFD software to simulate the water flow over the turbines as they are placed in a river to obtain the water flow characteristic. Different types of array arrangements are simulated in the river model. Multiple turbines are used to accumulate more power. The turbine model which consists of eight turbines is arranged in series with different spacing, ranging from a size of diameter (1D) to four times diameter (4D) of turbine is simulated to identify the optimum spacing between the turbines. Then, the simulation is continued using a sufficient spacing of $0.5 \mathrm{D}$ with angles ranging of $10^{\circ}$ to $60^{\circ}$ from datum of original position to minimise the disruption of the aquatic environment. The velocity profiles of each turbine are obtained and analysed. The $4 \mathrm{D}$ spacing and $40^{\circ}$ angle displayed higher average velocities compared to other arrangements. Thus, from this study, the $4 \mathrm{D}$ and $40^{\circ}$ are deduced as the optimum spacing and angle, respectively.
\end{abstract}

\section{Introduction}

The term pico hydropower is a small-scale hydropower with power generation of less than $5 \mathrm{~kW}$. It has made significant contributions to remote and off-grid settlements [1]. Installing and operating a run of river application, such as a pico hydrokinetic system is fully environment friendly as it does not alter the environment's natural course. This technology is favourable because of its constant supply of electrical energy and cost effectiveness in terms of low investment and maintenance costs [2]. The turbines can be installed in any flow with a velocity greater than $0.5 \mathrm{~m} / \mathrm{s}$ [3]. Kinetic energy from the flowing water can be converted into mechanical energy by rotating the turbine blade which then generates electricity.

Most computational researches on array arrangements are conducted for tidal turbines, which is comparable to run of river turbines [4]. Computational fluid dynamics (CFD) models are used to study and analyse wake effects. The simulations of the turbines are done using the boundary conditions as employed by $[4,5]$ to obtain the wake characteristics and comparing it later with experimental data.

A wake is the region of disturbed flow or recirculating flow immediately behind a stationary or moving solid body, caused by the fluid flowing around the body. The flow in this trail is slowed down and quite turbulent when compared with the flow arriving in front of the turbine. In incompressible fluids such as water, it results in a wave. Similar to all wave forms, it then spreads outward from the source until the energy it possesses is overcome or lost, normally by friction or dispersion [6].

According to A.S Bahaj et. al. [7], near wake may take the form of vortices shed from the tip of the blades or from the support structure and will bound the slower moving flow from the stream. A discontinuity in the stream velocity profile is created by these vortices. Usually the near wake exists from $0 \mathrm{D}-3 \mathrm{D} / 4 \mathrm{D}$, in which time the surrounding turbulence of the free flowing stream breaks down the bounding vortices.

Based on the study conducted by $\mathrm{Wu}$ et. al. [8], the formation and recovery of turbine wakes are known to be affected by the incoming flow characteristics, the operational states of a turbine and the turbine-generated turbulence characteristics. Both numerical and experimental studies of single turbine wakes in turbulent boundary layer flows has shown that the turbulence intensity level in the incoming flow can have a great effect on the wake recovery rate. A.S Bahaj et. al. [7] mentioned that the faster the free stream flows, the greater the convection of the wake. This means that the wake is carried further downstream in the same period of time. Therefore, the speed of the free stream is a key parameter in analysing the wake velocity.

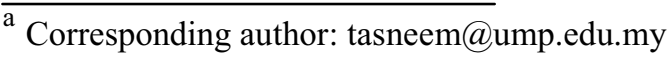


Study by Churchfield et. al. [9] reveals that the way in which the turbulent inflow is simulated greatly affects the wake propagation and power production of the array flow. From the study, it shows that the low speed wakes of the first row of turbines have an effect upon the second row. Hence, the wakes of the second row of turbines exhibit low stream velocities. The second row of turbine wakes also appears to contain more turbulent motions and meander significantly.

The work of Bai et. al. [5] presents the relative effect of increasing the inter row spacing and row spacing between TEC turbines. The results display that the array with larger width spacing shows the fluid entering the central TEC to be less influenced by the wakes from the upstream TEC row. Thus, this variation in performance highlights that there is an opportunity to modify spacing to fully optimise array performance.

The objectives of this study are to create a river model using CFD software and to simulate the water flow over multiple hydrokinetic turbines over different array arrangements to obtain the water flow characteristics. The aim is to obtain the optimum spacing and angle between the turbines which leads to higher turbine effective utilisation and performance in terms of power generated.

\section{Mathematical formulations}

\section{Governing equations}

In this study, the flow field is assumed to be incompressible, steady and non-isothermal flow. Therefore, the governing equations for the continuity, momentum and energy can be expressed as [10].

Continuity equation for incompressible flow:

$$
\begin{gathered}
\frac{\partial u}{\partial x}+\frac{\partial v}{\partial y}+\frac{\partial w}{\partial z}=0 \\
\vec{\nabla} \cdot \vec{V}=0
\end{gathered}
$$

where $u, v$ and $w$ are velocity components in the $x, y$ and $z$ directions, respectively, and $\vec{\nabla}$ is divergence operator.

Momentum equation:

$$
\begin{gathered}
\rho \frac{D \vec{V}}{D t}=\rho\left[\frac{\partial \vec{V}}{\partial t}+(\vec{V} \cdot \vec{\nabla}) \vec{V}\right] \\
=-\vec{\nabla} p+\rho \vec{g}+\mu \nabla^{2} \vec{V}
\end{gathered}
$$

where $\rho$ is density of the fluid $\left(\mathrm{kg} / \mathrm{m}^{3}\right), V$ is velocity vector of the fluid $(\mathrm{m} / \mathrm{s}), t$ is time (seconds), $g$ is gravitational acceleration $\left(\mathrm{m} / \mathrm{s}^{2}\right)$ and $\mu$ in the fluid viscosity $(\mathrm{kg} / \mathrm{m} . \mathrm{s})$.

Conservation of energy equation:

$$
\begin{aligned}
& \rho \frac{D E}{D t}=\frac{\partial\left(u \sigma_{x x}\right)}{\partial x}+\frac{\partial\left(v \sigma_{y y}\right)}{\partial y}+\frac{\partial\left(w \sigma_{z z}\right)}{\partial z} \\
& +\frac{\partial\left(u \tau_{y x}\right)}{\partial y}+\frac{\partial\left(v \tau_{z x}\right)}{\partial z}+\frac{\partial\left(v \tau_{x y}\right)}{\partial x}+\frac{\partial\left(v \tau_{z y}\right)}{\partial z} \\
& +\frac{\partial\left(w \tau_{x z}\right)}{\partial x}+\frac{\partial\left(w \tau_{y z}\right)}{\partial y}-\frac{\partial q_{x}}{\partial x}-\frac{\partial q_{y}}{\partial y}-\frac{\partial q_{z}}{\partial z}
\end{aligned}
$$

where $\sigma$ is stress and $\tau$ is shear stress.

Kinetic energy (KE) is the energy of motion. The kinetic energy of an object is the energy it possesses because of its motion. Kinetic energy equation is given as:

$$
K E=\frac{1}{2} m v^{2}
$$

where $K E$ represents kinetic energy $(\mathrm{J}), m$ is mass $(\mathrm{kg})$ and $v$ is the velocity $(\mathrm{m} / \mathrm{s})$.

The kinetic energy can be converted into mechanical energy. Kinetic energy from the flowing water can be converted into kinetic energy of rotating shaft by rotating the turbine blade. The formula below shows that velocity is directly proportional to the angular velocity:

$$
v=r \omega
$$

where $r$ is the radius (m) and $\omega$ is the angular velocity $(\mathrm{rad} / \mathrm{s})$.

The kinetic energy of a rotating object is analogous to linear kinetic energy and can be expressed in terms of the moment of inertia and angular velocity. For a given fixed axis of rotation, the rotational kinetic energy can be expressed in the form:

$$
K E=\frac{1}{2} I \omega^{2}
$$

where $I$ is the moment of inertia or rotational inertia $\left(\mathrm{kg} \cdot \mathrm{m}^{2}\right)$.

If a constant torque rotates a body through an angle $\theta$, the work done is:

$$
W=T \theta
$$

where $W$ is the work done $(\mathrm{J}), T$ is the torque $(\mathrm{J} / \mathrm{rad})$ and $\theta$ is the angle (rad).

The power of the rotating turbine blade is given by:

$$
P=T \omega
$$

where $P$ is power in watts (W). 


\section{Numerical analysis}

\subsection{Turbine and blade design}

The dimensions of the turbine blade are shown in Figure 1. All values are in millimetres $(\mathrm{mm})$.

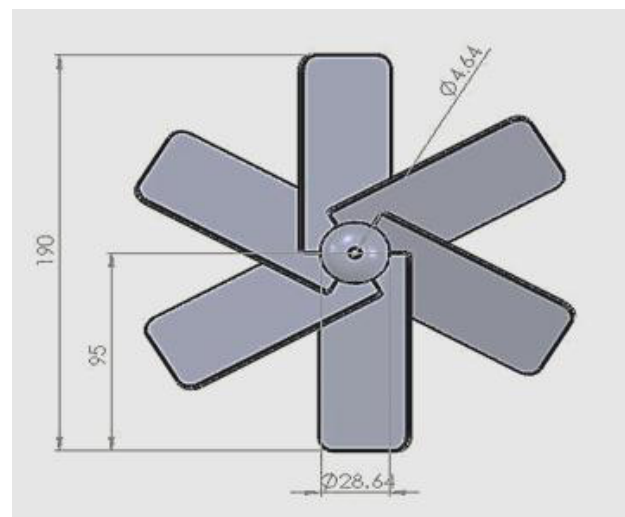

a) Front view

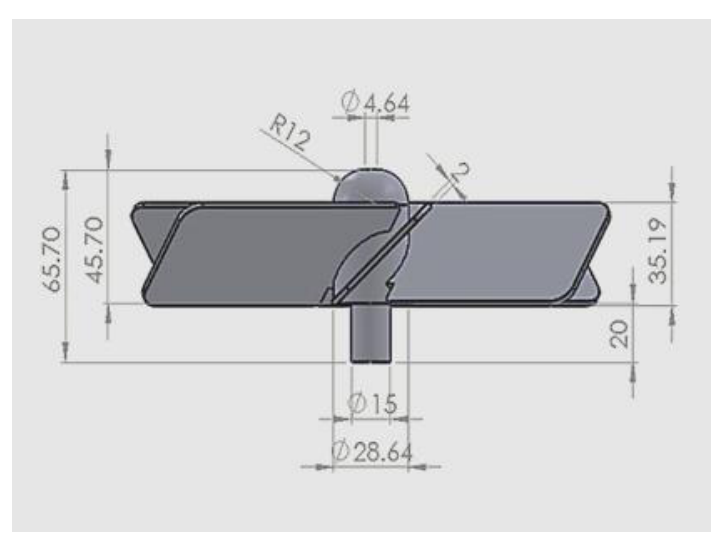

b) Side view

Figure 1. Dimensions of the blade

The blade is assembled to the turbine body as shown in Figure 2. For this study, eight identical turbines were used. The turbines were fitted through a shaft as shown in Figure 3.

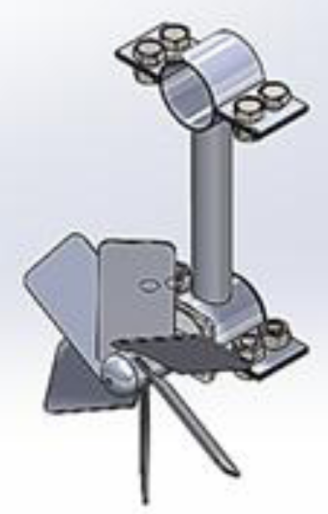

Figure 2. Turbine body

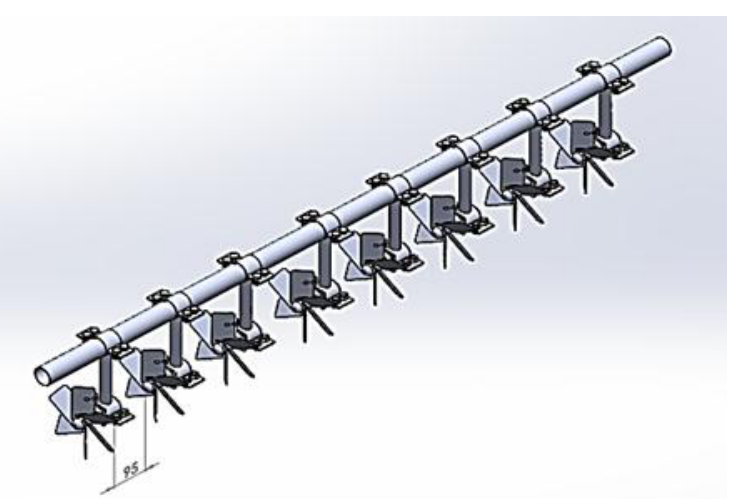

Figure 3. Full turbine arrangement

\subsection{Computational Domain}

The CFD software used is ANSYS 15.0 and the flow is studied using the Fluid Flow (CFX) analysis system. A river domain was set up using a box as an enclosure. The turbines were placed within the enclosure with the desired array arrangements of spacing and angle. Eight turbines are used for the simulation of different spacing while four turbines are used for the simulation of different angles.

\subsection{Meshing}

Fine mesh size is used on the model for every array arrangements. The number of element counts differs according to the spacing and angle between the turbines.

\subsection{Boundary Conditions}

For this study, the river flow was set as a steady flow fluid. As it is an open-channel flow, the fluid is composed of air (at the top) and water. However, the presence of air was neglected. The inlet velocity is $2.0 \mathrm{~m} / \mathrm{s}$ with equal upstream and downstream heights. Hence, the gradient of the river is zero. The upstream height is the height of water level of the river at the inlet and the downstream height is the height of the river water level at the outlet. The boundary conditions used in the simulation are summarised in Table 1.

Table 1. Boundary conditions of river model

\begin{tabular}{|c|c|}
\hline Boundaries & Parameter \\
\hline Inlet & Velocity $=2.0 \mathrm{~m} / \mathrm{s}$ \\
\hline Outlet & Constant static pressure \\
\hline Top surface & Zero pressure \\
\hline Sidewall & No slip wall \\
\hline Bottom & No slip wall \\
\hline
\end{tabular}




\subsection{Model configuration}

There are ten different array arrangements used for this study. The simulations were conducted on eight turbines which are arranged in series, as shown in Figure 4 and tested with different spacing, $x$. Four tests were conducted, in which $x$ is varied from a size of diameter (1D) to four times diameter (4D) of turbine, with an increment of 1D consecutively. D represents the diameter of the turbine blade, where D equals to $190 \mathrm{~mm}$.

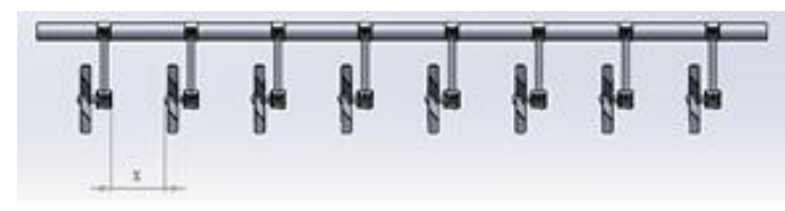

Figure 4. Turbine arranged in series

The simulation is continued by using four turbines with $0.5 \mathrm{D}$ spacing and tested with different angles, $\theta$. Angles, as in shown in Figure 5 are introduced with the aim to minimise the aquatic environment. Six tests were conducted, where $\theta$ is varied with angles of $10^{\circ}$ to $60^{\circ}$ from datum of original position, with an increment of $10^{\circ}$ consecutively.

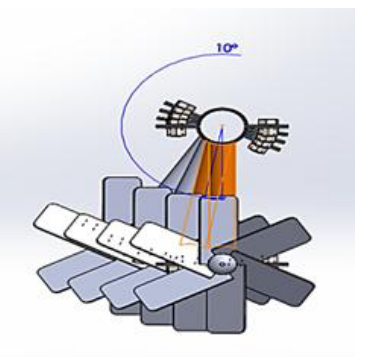

a)

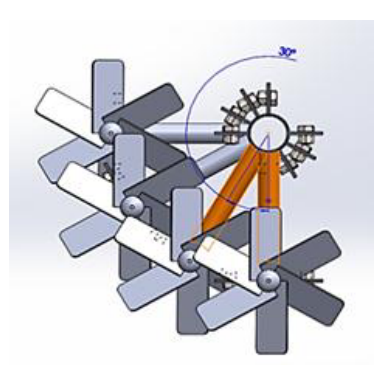

c)

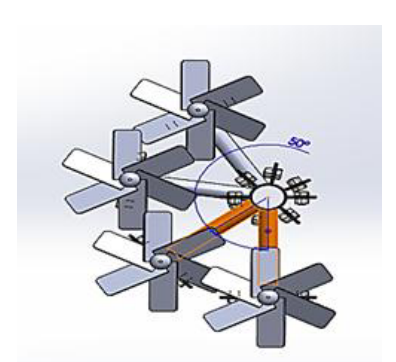

e)

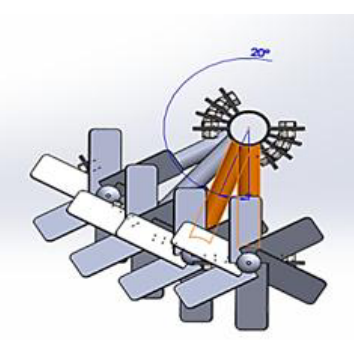

b)

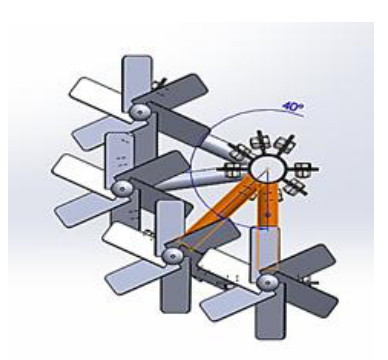

d)

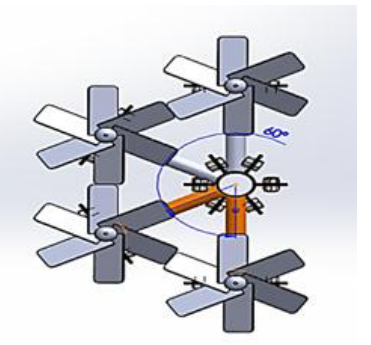

f)
Figure 5. Turbines arranged under the influence of angles; a) $10^{\circ}$, b) $20^{\circ}$, c) $30^{\circ}$, d) $40^{\circ}$, e) $50^{\circ}$ and f) $60^{\circ}$

\section{Results and discussion}

The CFD simulations and analysis were conducted to study the river water flow through the multiple hydrokinetic turbines of different spacing and angles. A comparison data is conducted to present the differences of velocity of each turbine in every arrangement. These simulations were carried out with a constant mean value of river velocity of $2.0 \mathrm{~m} / \mathrm{s}$ throughout ten different array arrangements with consists of four different spacing (1D, $2 \mathrm{D}, 3 \mathrm{D}$ and $4 \mathrm{D})$ and six different angles $\left(10^{\circ}, 20^{\circ}, 30^{\circ}\right.$, $40^{\circ}, 50^{\circ}$ and $60^{\circ}$ ).

For the velocity plots, velocity values at the entrance of the turbine were extracted from the line drawn across the mouth of the turbines. The values for all array arrangements were plotted for analysis. The higher the value of velocity at the turbine mouth, the higher the performance of the turbine. This is due to the higher kinetic energy in the flow. The average velocity for each array arrangement is calculated to determine the best arrangement to generate maximum power.

\subsection{Spacing}

Figure 6 displays the changes in velocities of the river water as it flows throughout the turbines. It shows that the velocity of the flow decreases as it passes through the turbines. Figure 6a) shows a large drop in velocity occurs as the water passes through the turbines of 1D spacing and the velocity remains low at the mouth of each turbine. However, as the spacing increases, the water velocity starts to recover slowly as it flows over a distance. Figure 6b) shows a slight increase in velocity as well as in Figure 6c), which exhibits a higher increase in velocity. Based on the four tests, the 4D spacing arrangement in Figure 6d) shows the highest velocity at the mouth of each discrete turbine. 


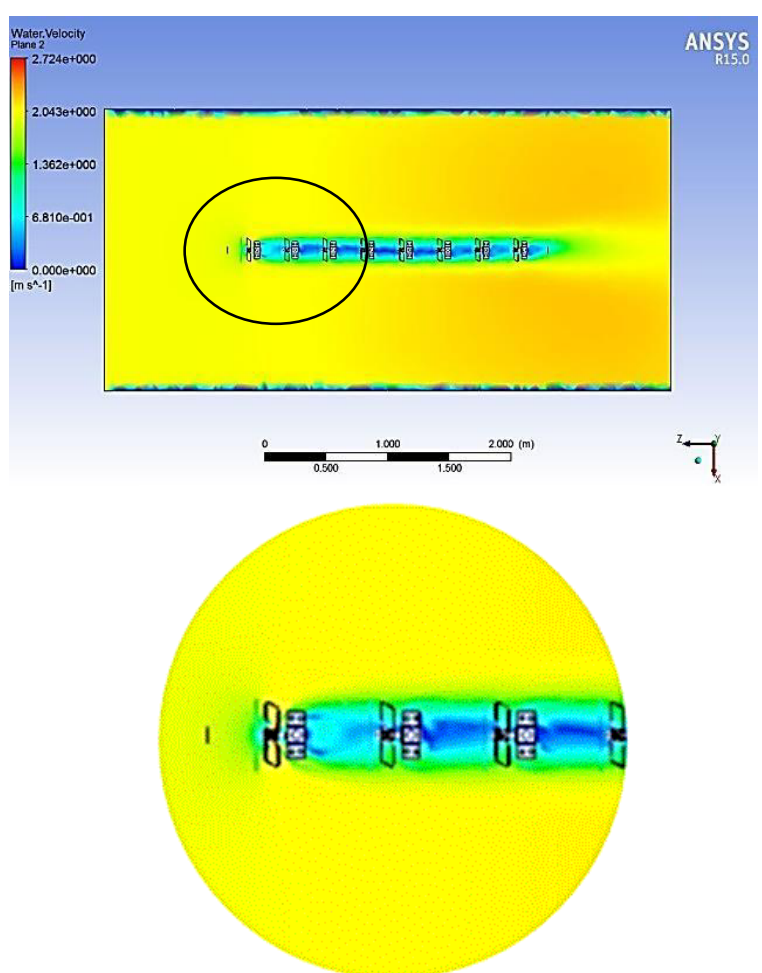

a) $1 \mathrm{D}$

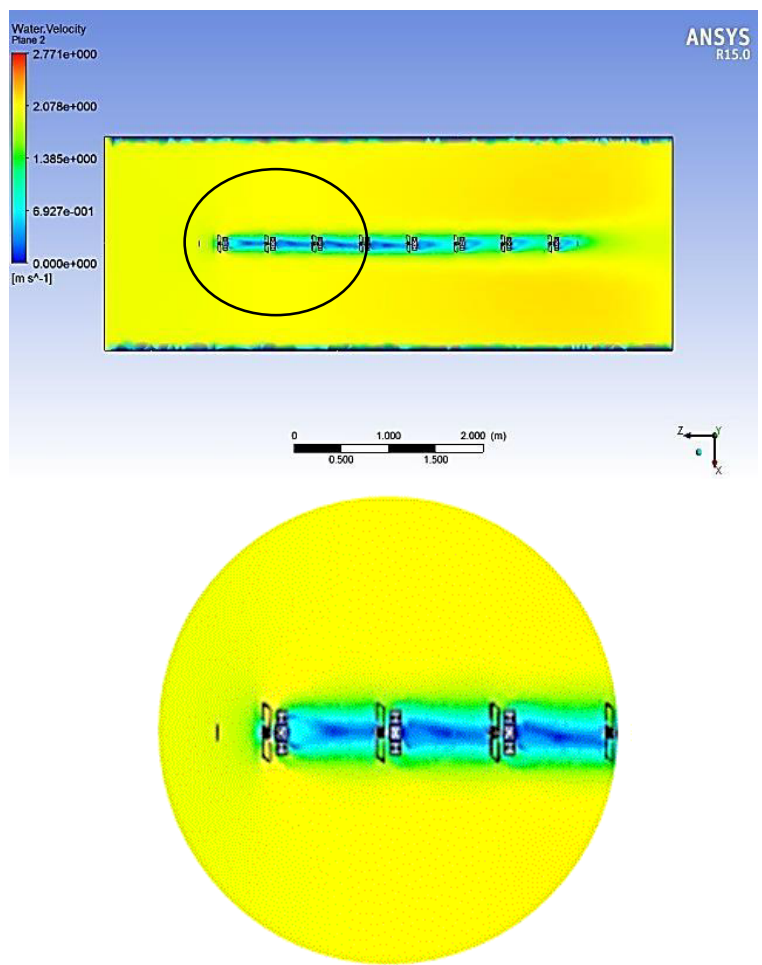

b) $2 \mathrm{D}$
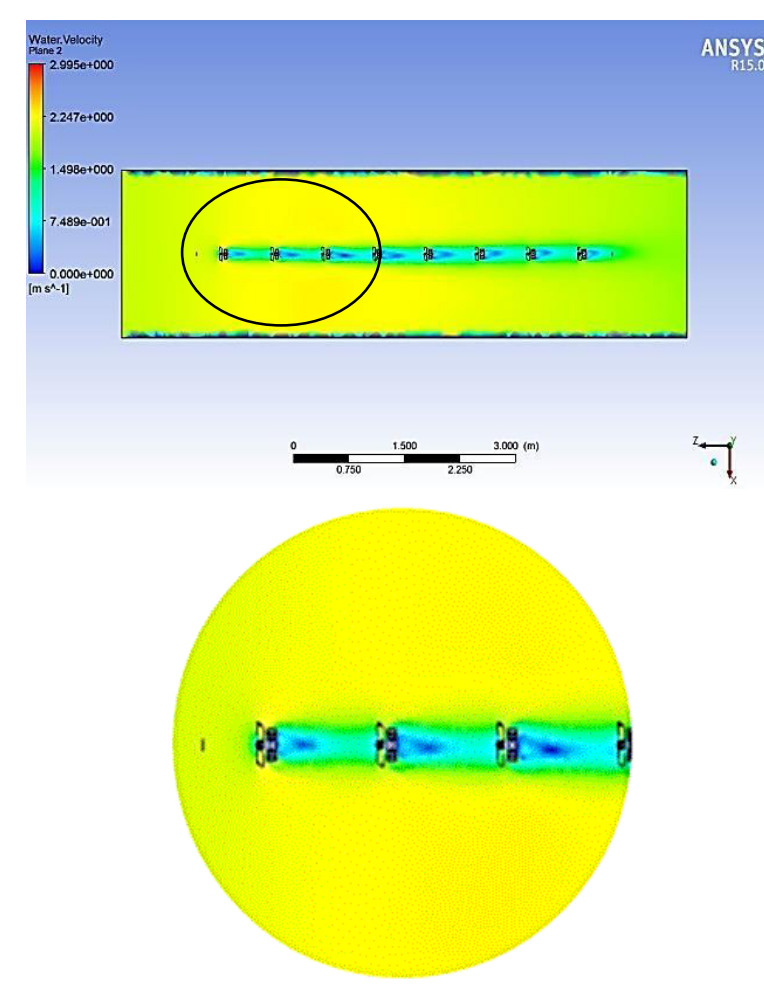

c) $3 \mathrm{D}$
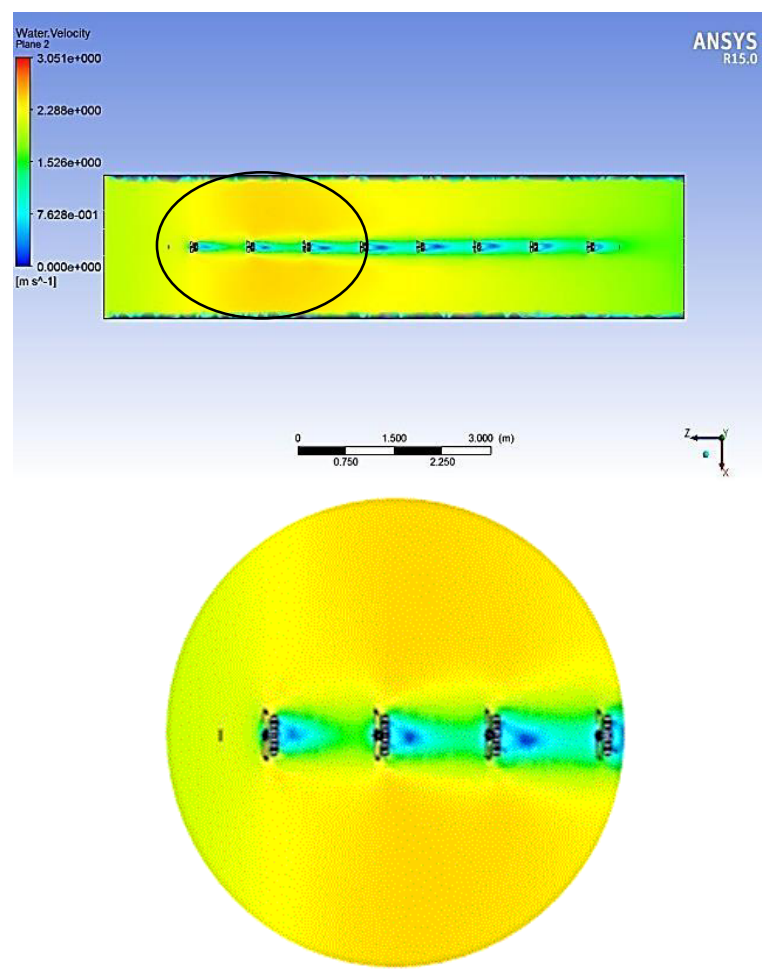

d) $4 \mathrm{D}$

Figure 6. Velocity planes from simulation results of turbines with different spacing 


\subsection{Angle}

Figure 7 displays the arrangement of turbines with different angles and its velocity profiles. Figure 7a) shows a large drop in velocity occurs as the water passes through the turbines with $10^{\circ}$ angle and the velocity at the mouth of each discrete turbine remains low. However, as the angle increases, the velocity at the mouth of each discrete turbine also increases. Based on the six tests, it can be concluded that when the angle increases, the position of the turbine moves away from the low velocity region that forms behind each turbine. Hence, Figure 7f) with the $60^{\circ}$ angle arrangement exhibits the highest velocity.

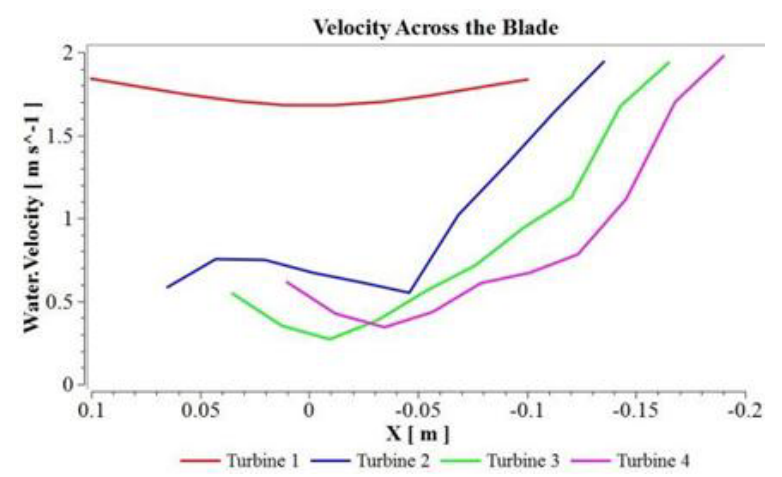

a) $10^{\circ}$

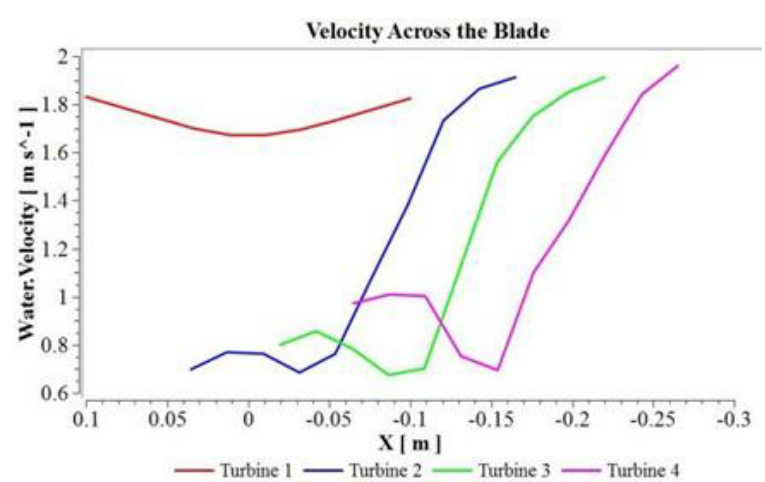

b) $20^{\circ}$

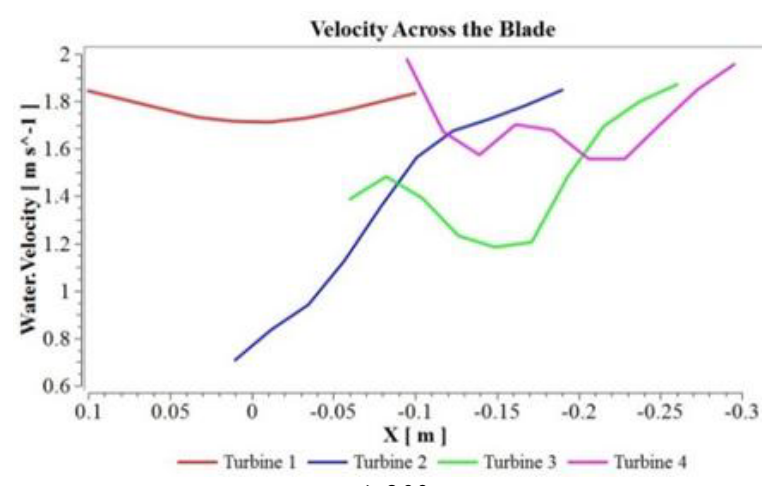

c) $30^{\circ}$
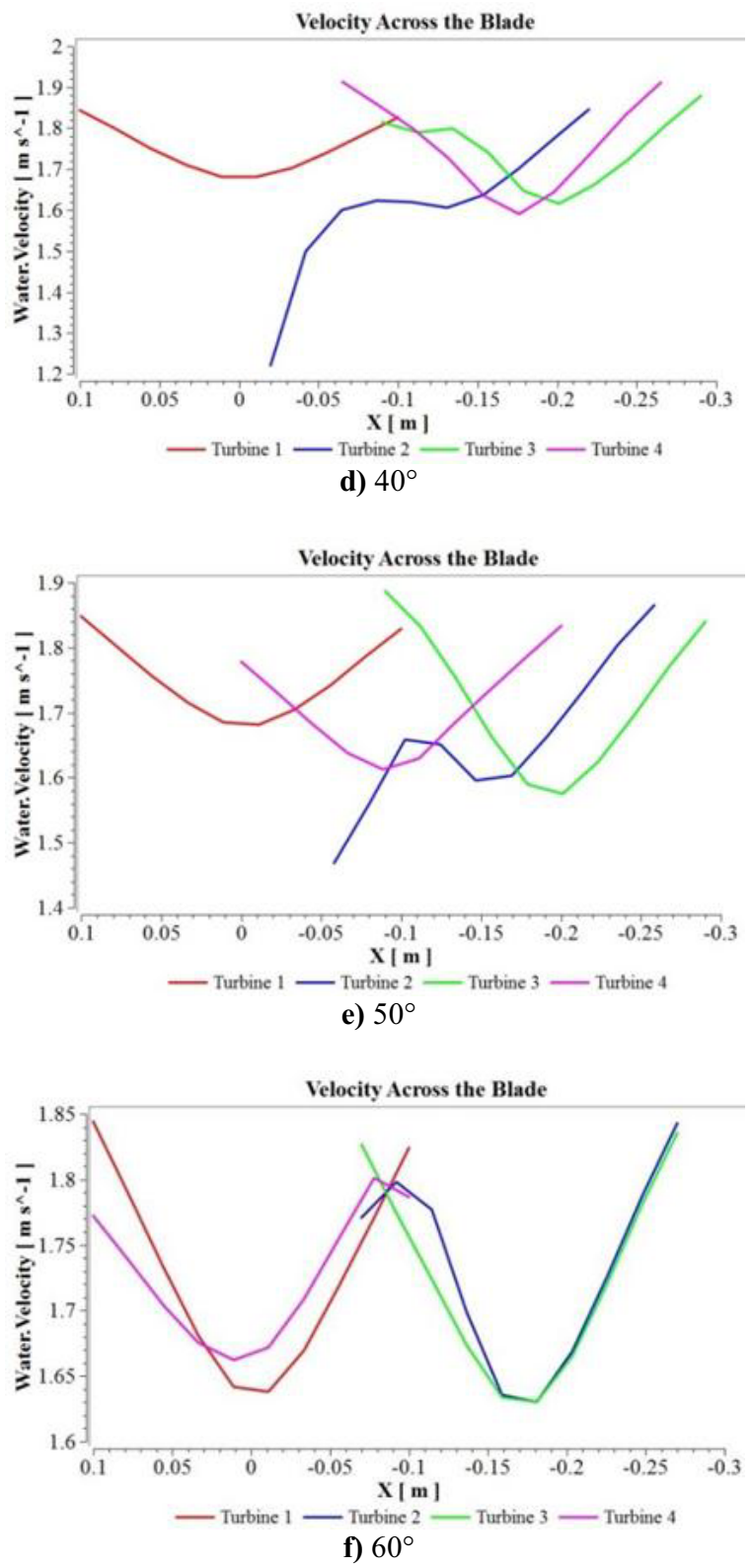

Figure 7. Velocity plots from simulation results of turbines with different angles 


\subsection{Comparison between arrangements}

Based on the tests conducted, the average velocity of each spacing and angle arrangement is obtained from the velocity plot and the results are tabulated in Table 2 and Table 3 respectively.

Table 2. Average velocity respective to their spacing

\begin{tabular}{|c|c|}
\hline Spacing (mm) & Average velocity (m/s) \\
\hline $190(1 \mathrm{D})$ & 1.022 \\
\hline $380(2 \mathrm{D})$ & 1.156 \\
\hline $570(3 \mathrm{D})$ & 1.292 \\
\hline $760(4 \mathrm{D})$ & 1.458 \\
\hline
\end{tabular}

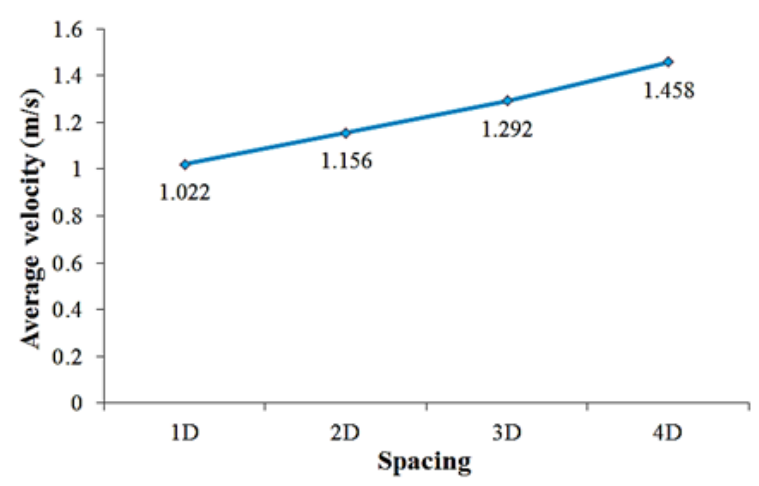

Figure 8. Graph of average velocity versus spacing

Figure 8 shows the effect of spacing onto the average velocity at the mouth of each discrete turbine. In the series arrangement of the turbines, the average velocity increases as the spacing increases. Based on the graph, the $760 \mathrm{~mm}$ (4D) spacing arrangement shows the highest average velocity at the mouth of each discrete turbine. Hence, the larger the spacing between the turbines, the higher the velocity obtained. Therefore, larger spacing is needed to generate maximum power.

Table 3. Average velocity respective to their angle

\begin{tabular}{|c|c|}
\hline Angle $\left.\mathbf{(}^{\circ}\right)$ & Average velocity $(\mathbf{m} / \mathbf{s})$ \\
\hline 10 & 1.318 \\
\hline 20 & 1.417 \\
\hline 30 & 1.588 \\
\hline 40 & 1.699 \\
\hline 50 & 1.722 \\
\hline 60 & 1.736 \\
\hline
\end{tabular}

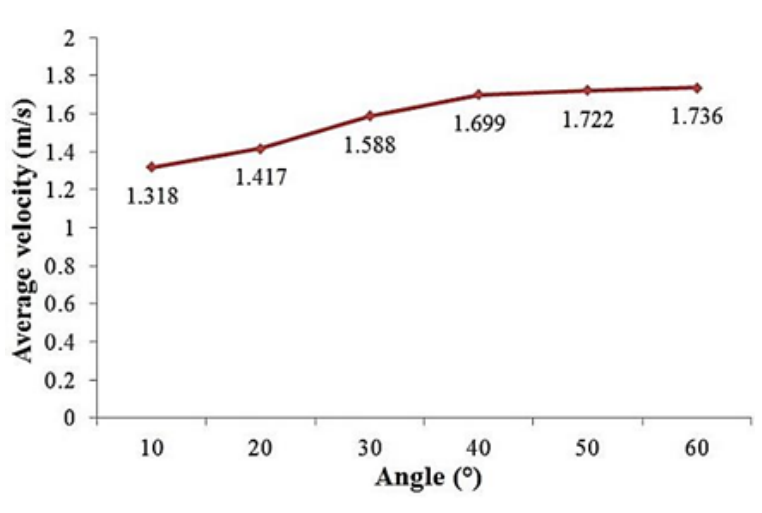

Figure 9. Graph of average velocity versus angle

Figure 9 shows the effect of angle onto the average velocity at the mouth of each discrete turbine. The average velocity increases as the angle increases. Based on the graph, the $60^{\circ}$ angle arrangement shows the highest average velocity at the mouth of each discrete turbine. However, it can be noticed from the graph that the angle of $40^{\circ}$ is able to achieve higher velocity compared to smaller angles and the velocity at angle greater than $40^{\circ}$ does not increase much and remains about the same. Therefore, angle greater than $40^{\circ}$ is needed to generate maximum power.

\section{Conclusions}

In this study, the effect of velocity flow over different array arrangements could be studied and analysed. Based on the simulation results obtained, it is proven that for a series arrangement of turbines, the larger the spacing between the turbines, the higher the velocity obtained. High velocity is necessary to generate maximum power. Small spacing does not show signs of good performance due to its low average velocity throughout the turbines. Based on the tests conducted on the different spacing, the results show that the spacing of $4 \mathrm{D}$ exhibits the highest average velocity. Therefore, it is concluded as the optimum spacing between the turbines.

However, the application of hydrokinetic turbines in rivers might be restricted to the aquatic environment available at a particular area. Therefore, when taking that into consideration, angle spacing should be considered in the turbine arrangement to minimise the area involved for the installation of the turbines. From the tests conducted on different angles, $60^{\circ}$ angle shows the highest velocity obtained. However, it is found that the angle of $40^{\circ}$ is sufficient enough to be considered as the optimum angle where maximum power can be generated as it is capable in achieving higher velocity compared to smaller angles. Therefore, angles greater than $40^{\circ}$ are applicable.

All discussions and results obtained are based on software simulation only. Due to the limitations of the study, the effect of the rotation of the turbine blades to the water flow is not considered. Hence, the results of this study should not be applied thoroughly without 
considering other possible factors when dealing with fluid flow.

For future application of hydrokinetic turbines, spacing and angle should both be accounted in order to achieve maximum power generation and to overcome environmental limitations as well as minimising the disruption of aquatic environment.

\section{Acknowledgements}

The authors would like to thank Centre for Earth Resources Research \& Management (CERRM), Universiti Malaysia Pahang for providing financial assistance under project no. RDU140345.

\section{References}

1. S. Kamaruzzaman and A.R. Juhari, Pico Hydro: Clean Power From Small Streams. 3rd WSEAS Int. Conf. on Renewable Energy Source, 1-6 (2009)

2. R. Kapoor, Pico Power: A Boon for Rural Electrification, Advance in Electronic and Electric Engineering, 3, 865-872 (2013)

3. S. Kari, Small-scale Water Current Turbines for River Applications, 4 (2010)
4. M.A. At-tasneem, et al., Numerical Simulation of Multiple Arrays Arrangement of Micro Hydro Power Turbines. World Academy of Science, Engineering and Technology International Journal of Mechanical, Aerospace, Industrial and Mechatronics Engineering, 8, 966-972 (2014)

5. L. Bai, R.R.G. Spence and G. Dudziak, Investigation of the Influence of Array Arrangement and Spacing on Tidal Energy Converter (TEC) Performance using a 3-Dimensional CFD Model. 8th European Wave and Tidal Energy Conference, Uppsala, Sweden, 654-660 (2009)

6. Ximo, C.O.M, Wake, Ject Press (2012)

7. A.S. Bahaj, et al., Characterising the wake of horizontal axis marine current turbines. 7th European Wave and Tidal Energy Conference, Porto, Portugal, (2007)

8. Y.T. Wu and P. Fernando, Atmospheric Turbulence Effects on Wind-Turbine Wakes: An LES Study, 123 (2012)

9. M.J. Churchfield, Y. Li, and P.J. Moriarty, A LargeEddy Simulation Study of Wake Propagation and Power Production in an Array of Tidal-Current Turbines, 1-10 (2011)

10. Y.A. Cengel and J.M. Cimbala, Fluid Mechanics: Fundamentals and Application, New York: McGrawHil (2013) 